\title{
Aortic atresia: survival to adulthood without surgery
}

\author{
Patrick Maxwell, Jane Somerville
}

\begin{abstract}
Aortic atresia is a rare congenital cardiac defect. It usually leads to death in the neonatal period. A patient with aortic atresia has survived to the age of 24 years without any surgical procedure. In view of the uncertain results of reconstructive surgery this case may have therapeutic implications.
\end{abstract}

Aortic atresia is a rare congenital cardiac defect that is usually associated with the hypoplastic left heart syndrome and is fatal in the newborn. Surgical techniques can prolong life. ${ }^{1}$ We report survival to adult life without surgery of a patient with aortic atresia.

\section{Case report}

The patient, a man aged 24 , has aortic atresia with a normal sized left ventricle, a large ventricular septal defect, and a patent ductus arteriosus.

He was the product of a normal pregnancy with no family history of congenital heart disease. After birth he briefly required oxygen for cyanosis. No abnormalities were detected at this time and he left hospital after the normal postnatal period. When he was a month old he was admitted to The Hospital for Sick Children, Great Ormond Street, with chronic feeding difficulties. He was not cyanosed but was reported to have heart failure with intercostal recession with an electrocardiogram showing left ventricular hypertrophy and cardiomegaly with plethoric lung fields on the chest radiograph. Cardiac catheterisation showed contrast passing into the minute ascending aorta via a patent duct. The left atrium and left ventricle were of normal dimensions with the left ventricle emptying into a huge pulmonary artery through a large ventricular septal defect. The table shows the oxygen saturations and pressures recorded. Treatment with digoxin and diuretics was started and he improved. By the age of one year he had become cyanosed. When he was five years old he had a poor exercise tolerance, frequent respiratory tract infections, and established clubbing of the fingers with central cyanosis. Cardiac catheterisation showed features of the Eisenmenger syndrome (table).

$\mathrm{He}$ was referred to the National Heart Hospital at the age of 15 . He was more cyanosed and the haemoglobin concentration was $230 \mathrm{~g} / 1$. In view of the polycythaemia, regular venesection with volume replacement was started. The chest $x$ ray showed moderate cardiomegaly, enlargement of the proximal pulmonary arteries, and oligaemic lung fields. Electrocardiography showed right atrial and biventricular hypertrophy. Cardiac catheterisation showed that there was no flow across the aortic valve and that oxygen saturation was identical in the pulmonary artery and abdominal aorta (table). The figure shows the hypoplastic aortic root and the coronary arteries, which were perfused retrogradely from the patent duct.

Now aged 24 he has signs of pulmonary hypertension and incompetence with deep cyanosis. His fingers and toes are equally clubbed. He has recurrent small haemoptyses. He works full time and has moderate limitation from dyspnoea (ability index 2). Heartlung transplantation will be considered when he becomes more limited; a long transverse anastomosis with the donor arch will be required.
Dr Patrick Maxwell, Renal Unit, Guy's Hospital, St Thomas Street, London SE1 9RT.
National Heart

Hospital,

P Maxwell

J Somerville

Data from cardiac catheterisation at three different ages

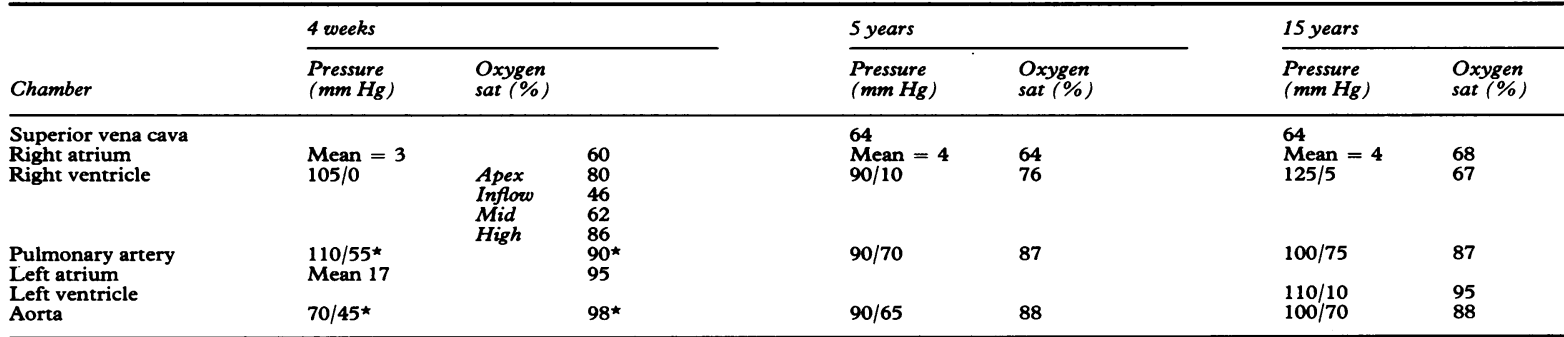

*These readings in the aorta were not simultaneous with those in the pulmonary artery. Presumably simultaneous readings would have given the same value in both, as in the later studies. 
Angiogram (anteriorposterior view with caudal tilt) at 15. The catheter is in the aortic arch, inserted via the right brachial artery. Contrast is seen filling the ascending aorta which is hypoplastic, and the coronary arteries.

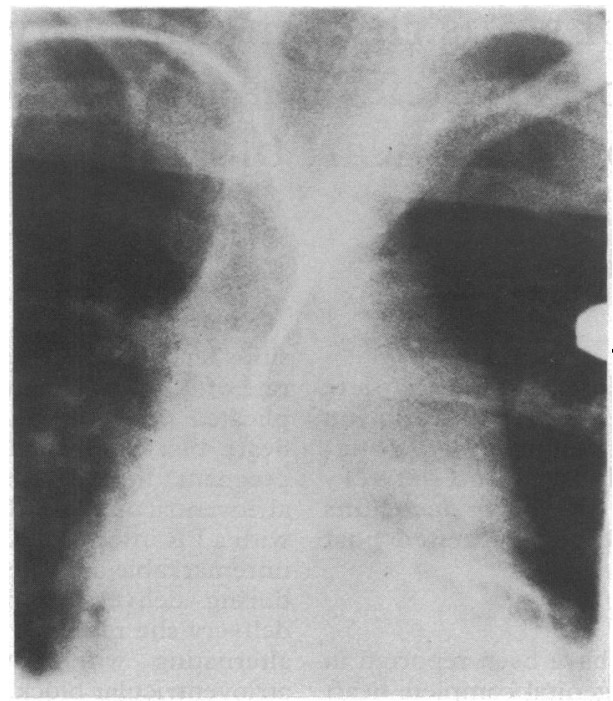

\section{Discussion}

Aortic atresia is a feature of "hypoplasia of the aortic tract complexes". 2 Most cases have associated left ventricular hypoplasia and mitral atresia so they are grouped within the "hypoplastic left heart syndrome". ${ }^{3}$ In our patient, however, there was a normal left ventricle, which has been reported in $4 \%$ of cases. ${ }^{45}$ This occurs when there is no reduction of inflow (mitral atresia or stenosis). The outlook for those with a normal and those with hypoplastic left ventricles, however, was much the same, with a mean age at death of five days. The longest survival in these necropsy series was 56 days. The longest previously reported survival of any child with aortic atresia is three years. ${ }^{6}$

Why has our patient survived for so long? The anatomy of the heart was favourable in three ways. Firstly, he is one of the few patients with aortic atresia who has a normal left ventricle. Secondly, his ventricular septal defect was large enough not to restrict outflow from the left ventricle. Thirdly, in the neo- natal period he had a large ductus arteriosus. It was essential that this should stay patent, and it did. In addition, there was no coarctation of the aorta.

Presumably pulmonary vascular resistance was relatively low initially, permitting a high pulmonary blood flow. This allowed good oxygenation, but also caused pulmonary congestion. This initial situation clearly permitted survival beyond infancy. The function of the left ventricle did not deteriorate because its outflow, via the ventricular septal defect, was not restricted. Since infancy the pulmonary vascular resistance has increased, pulmonary blood flow has fallen, and the coronary arteries are perfused retrogradely with blue blood. The patient thus lives on as a case of the Eisenmenger reaction. Such patients (with different cardiac anatomy) have survived into the sixth decade.

It seems that in cases of aortic atresia with a large ventricular septal defect and normal left ventricle, medical attention in infancy might best be directed at keeping the pulmonary vascular resistance high and the duct permanently open by pharmacological treatment. This could be as effective as reconstructive surgery in prolonging life, or even more effective, and cause considerably less suffering, risk, and expense. Also, avoidance of a thoracotomy would improve the chances of successful heart-lung transplantation later in life.

1 Norwood WI, Lang P, Hansen DD. Physiologic repair of aortic atresia-hypoplastic left heart syndrome. $N$ Engl $J$ Med 1983;308:23-6.

2 Lev M. Pathologic anatomy and interrelationship of hypoplasia of the aortic tract complexes. Lab Invest 1952;1: 61-70.

3 Noonan JA, Nadas AS. The hypoplastic left heart syndrome. An analysis of 101 cases. Pediatr Clin North Am 1958;5: 1029-56.

4 Roberts WC, Perry LW, Chandra RS, Myers GE, Shapiro SR, Scott LP. Aortic valve atresia: a new classification SR, Scott LP. Aortic valve atresia: a new classification 37:733-56.

5 Freedom $M$, Dische $M R$, Rowe RD. Conal anatomy in aortic atresia, ventricular septal defect, and normally developed left ventricle. Am Heart $J$ 1977;94:689-98.

6 Moodie DS, Gallen WJ, Friedberg DZ. Congenital aortic atresia: report of long survival and some speculation about surgical approaches. $J$ Thorac Cardiovasc Surg 1972;63: 726-31. 